\title{
A Descentralização Administrativa no Serviço Público Federal
}

\section{CaIo TácIto}

\section{MESA REDONDA DE LIÈGE}

$R$ ealizou-se, de 27 de junho a 3 de julho próximos findos, em Liège, Bélgica, a reunião anual do Instituto Internacional de Ciências Administrativas, do qual a Seção Brasileira é o Instituto Brasileiro de Ciências Administrativas.

Representou o Govêrno Brasileiro nessa reunião o $D r$. Luiz Simões Lopes, Presidente do Instituto Brasileiro de Ciências Administrativas e Vice-Presidente do Instituto Internacional de Ciências Administrativas. Como representantes do I.B.C.A. participaram da reunião os Srs. Dr. AdROAldo Tourinho Junqueira Ayres e J. M. Santos Araujo CavalCANTI, Secretário Geral do I.B.C.A. O Ministério da Viação e Obras Públicas também enviou um delegado, o Dr. A. FonsecA Pimentel, Diretor Geral do Departamento de Administração do Ministério.

Os temas debatidos em Liège foram os seguintes:

- Descentralização Administrativa (criação, desenvolvimento e situação atual das autarquias, sociedades de economia mista e fundações). O I.B.C.A. apresentou contribuição escrita, elaborada pelo Prof. CAIo TÁCITO;

- Automação e sua aplicação nos serviços administrativos (levantamento dos projetos já executados e em. fase de planejamento). Como ainda não possuem os serviços administrativos federais, quer já implantados, quer em fase de planejamento, serviços automatizados, o I.B.C.A. não apresentou o levantamento pro- 
gramado. Participou, porém, por intermédio dos representantes brasileiros, do estudo da matéria;

- Processos de informação da Administração (processos adotados pela administração para informar-se, antes de tomar uma decisão externa de caráter geral, compreendendo: coleta da documentação já existente, consulta a órgãos internos de deliberação coletiva criados para fins de aconselhamento e a órgãos externos de colaboração; e recurso a audiências, investigações especiais e inquérito de opinião). O I.B.C.A. apresentou trabalho por escrito, elaborado pela Prof. ${ }^{a}$ BeAtriz M. DE SouzA WAHRLICH.

Oportunamente, publicará a $R$. S. P. um resumo dos debates havidos. Nèste número, abrimos espaço para apresentar o trabalho elaborado pelo Prof. CaIo TÁcito: "Descentralização Administrativa".

I - O tema proposto visa ao estudo dos entes autôncmos que, dotados de personalidade jurídica própria, exercem uma atividade específica de administração: A sua instituição, decorrente de lei, corresponde a uma dupla necessidade, sensível modernamente em todos os países: uma, de caráter orgânico, consistente na especialização do serviço atribuído ao órgão administrativo; outra, de ordem funcional, que se caracteriza pela autonomia administrativa, facultando ao ente personalizado maior flexibilidade, notadamente no regime financeiro.

A experiência brasileira oferece, a êsse propósito, importante ccntribuição, tanto pelo vulto das instituições descentralizadas, como pelo lapso apreciável de tempo em que a União se tem utilizado dessa forma de gestão do serviço público.

Não se cogita, no desenvolvimento dêsse trabalho, da descentralização política, resultante do regime federativo, pelo qual, nos têrmos da organização constitucional brasileira, o Estado Federal se desdobra em 20 Estados, 4 Territórios, um Distrito Federal e 2.468 Municípios, cada um dêles dotados de serviços administrativos próprios. Em certos Estados e $\mathbf{M u}$ nicípios, a descentralização administrativa tem sido aplicada, nos últimos anos, com resultados satisfatórios.

A nossa exposição ficará, porém, limitada aos quadros de administração pública federal, em obediência ao temário que, expressamente, elimina o estudo dcs podêres locais.

II - O Poder Executivo federal compõe-se de órgãos de administracão direta, subordinados à Presidência da República ou a um dos onze Ministérios (oito civis e três militares) e de órgãos de administração indireta ou descentralizada. 
Os órgãos de administração indireta, criados em lei, com personalidade jurídica própria, dotados de autonomia administrativa e financeira, assim se distribuem:

a) 68 autarquias, sendo:

3 diretamente subordinadas ao Presidente da República

26 subordinadas ao Ministério da Fazenda

15 subordinadas ao Ministério do Trabalho, Indústria e Comércio

8 subordinadas ao Ministério da Educação e Cultura

7 subordinadas ao Ministério da Viação e Obras Públicas

6 subordinadas ao Ministéric da Agricultura

1 subordinada ao Ministério das Relações Exteriores

1 subordinada ao Ministério da Guerra

b) 19 Sociedades de economia mista $e$

c) 7 Fưndações.

O Regime jurídico e administrativo dessas entidades é fixado na respectiva lei institucional e se apresenta, em cada caso, com aspectos: próprios, em função dos encargos que lhe são atribuídos.

Certos característicos gerais, peculiares a cada categoria, possibilitam, no entanto, a classificação sistemática dos órgãos personalizados da administração indireta.

As autarquias são pesscas jurídicas de direito público, com finalidade determinada, autonomia administrativa e patrimcnial, sujeitas à supervisão e contrôle da administração direta. São mantidas com receita própria, proveniente da arrecadação de contribuições parafiscais específicas ou de verbas orçamentárias da União e gozam de imunidade tributária. Além do contrôle administrativo e financeiro direto e imediato, exercidc por meio de Conselhos Fiscais ou Juntas de ccntrôle através de departamentos ministeriais, estão sujeitas, ainda, ao exame anual de sua gestão financeira pelo Tribunal de Contas da União. O seu pessoal está equiparado por lei aos servidores civis da União.

As sociedades de eccnomia mista, organizadas como sociedades anônimas, na forma da lei comercial, mediante autorização legislativa, são pessoas jurídicas de direito privado, destinadas a atividades bancárias, securitárias ou industriais. A União subscreve, obrigatòriamente, pelo menos $51 \%$ do capital social, garantindo, dessa forma, como acionista majoritário, a direção da companhia. A relação de emprêgo de seus servidores, embora regida pela legislação trabalhista, equipara-se acs cargos públicos, para efeito da vedação constitucional de acumulação.

As fundações, moldadas nas instituições de direito civil, obedecem a regime jurídico especial de direito público. Auferem recursos oriundos da receita pública e exercem atribuições culturais, educacionais, assistenciais ou habitacionais definidas em lei federal, gozando de certos privilégios do poder público. 
Vamos considerar, a seguir, cada uma dessas categorias de órgãos autônomos, em relação aos pontos seguintes, destacados no tema da ordem do dia da reunião:

a) processo de delegação de podêres às instituições;

b) relação entre as instituições e o Estado;

c) organização e gestão, inclusive financeira, das instituições.

\section{AUTARQUIAS}

As autarquias se caracterizam pela personalidade jurídica, a autonomia administrativa e financeira (de que resulta a autonomia patrimonial) e a especialização dos fins.

A lei que as institui determina o limite de atribuições delegadas ao órgão, que se completa, do ponto de vista normativo, pelos atos regulamentares, baixados pelo Presidente da República, no uso da faculdade constitucional de prover à execução das leis.

Entre as incumbências conferidas a entidades autárquicas federais destacam-se, pela sua importância, as seguintes:

a) o sistema federal de previdência social aos trabalhadores e servidores públicos, executado por meio de oito instituições autônomas, que arrecadam e aplicam contribuições parafiscais incidentes sôbre cs salários e vencimentos;

b) o sistema de ensino superior oficial, distribuído em oito Universidades, mantidas com verbas orçamentárias globais;

c) o sistema de Caixas Econômicas Federais, compostas de 22 estabelecimentos, com sede no Distrito Federal e Estados, fiscalizadas pelo ConseTho Superior das Caixas Econômicas Federais, que funcionam como bancos de depósitos, aplicando suas disponibilidades, especialmente, em empréstimos hipotecários;

d) Banco Nacional de Desenvolvimento Econômico, que funciona como estabelecimento bancário oficial nas operações financeiras de reapare1hamento e fomento da economia nacional, movimentando recursos internos e créditos externos;

e) entidades de contrôle da produção, como o Instituto Brasileiro do Café, o Instituto do Açúcar e Álcool, o Instituto Brasileiro do Sal, o Instituto Nacional do Pinho e o Instituto Nacional do Mate;

f) ordens profissionais, incumbidas do registro e fiscalização de certas atividades, como o Conselho Federal de Contabilidade, o Conselho Federal dos Economistas Profissionais, o Conselho Federal de Engenharia e Arquitetura, o Conselho Federal de Química e o Conselho Federal de Medicina. A Ordem dos Advogados do Brasil é entidade colaboradora da Administração federal, instituída em lei, ccm personalidade jurídica própria, sem caráter autárquico definido;

g) entidades relacionadas com o transporte terrestre e marítimo, comu o-Departamento Nacional de Estradas de Rodagem, a Administração do Pôr- 
to do Rio de Janeiro e emprêsas oficiais de navegação marítima (Lloyd Brasileiro, Serviço de Navegação do Amazonas e da Bacia do Prata);

h) entidades de caráter científico, ccmo o Conselho Nacional de Pesquisas e o Instituto Brasileiro de Geografia e Estatística, ou de finalidades especiais, como o Serviço Social Rural, ou o Instituto Nacional de Imigração e Colonização.

As autarquias se colocam sob tutela administrativa do Estado, que também exerce, sôbre elas, poder hierárquico limitado.

Os seus dirigentes são livremente escolhidos pelo Presidente da República, podendo ser dispensados ad nutum, salvo casos especiais de mandato a prazo determinado. As situações jurídicas do pessoal das autarquias são constituídas e modificadas mediante atos da respectiva administração, sujeitos a recurso para os órgãos ministeriais e, eventualmente, ao Presidente da República. A criação e extinção de cargos é feita mediante decreto do Presidente da República. O provimento dos cargos e funções é, legalmente, da competência do dirigente da autarquia, mas depende, em cada caso, de prévia autorização do Presidente da República.

Os orçamentos das autarquias são aprovados pelo Poder Executivo, que também fiscaliza a execução orçamentária. Não há qualquer participação do Congresso na gestão financeira das autarquias, como dos demais órgãos descentralizados. O princípio constitucional da unidade orçamentária não se estende à receita e despesa dessas entidades.

A administração das autarquias se organiza, geralmente, sob forma presidencial: a Direção cabe a um Presidente, assistido por Diretores e órgãos locais, nos Estados. Certos atos, especialmente de caráter financeiro, depen. dem de homologação de órgãos colegiados da própria autarquia, ou de auto. ridades ministeriais.

O sistema autárquico federal não se encontra disciplinado em leis gerais sôbre a gestão administrativa dessas instituições. A não ser quanto ao regime de pessoal, que obedece a uma certa padronização legislativa, as normas jurídicas sôbre organização e funcionamento das autarquias são muito variáveis, segundo a legislação especial de cada uma dessas pessoas de direito público.

Não obstante essa diversificação orgânica e funcional, a experiência dos últimos anos permite assinalar duas tendências marcantes na prática administrativa. De um lado, observa-se uma progressiva limitação da autonomia de direção nas artarquias. Atos regulamentares cu simples atos administra. tivos gerais condicionam a competência legal dos administradores autárquicos, estabelecendo a autorização prévia do Presidente da República para certas decisões, como, por exemplo, a nomeação de funcionários ou a concessão de empréstimos imobiliários.

De outra parte, acentua-se, recentemente, a influência de correntes politicas na escolha dos dirigentes autárquicos, tanto nos órgãos de direção geral, como nos órgãos secundários de execução. E' prematuro extrair conciusões dêsse fenômeno que, a longo prazc, poderá diminuir o rendimento técnico e a isenção nos programas administrativos. 


\section{SOCIEDADES DE ECONOMIA MISTA}

Como expressão típica de intervenção no domínio econômico, as socie. dades de eccnomia mista representam, no direito brasileiro, a forma de monopólio ou concorrência da União em determinadas indústrias ou atividades.

Dependentes de lei que autorize a subscrição majoritária do capital, essas sociedades são constituídas, registradas e geridas de acôrdo com o direito comercial, ressalvados certos podêres de tutela reservadcs, por lei, ao Estado. São pessoas jurídicas de direito privado e o seu pessoal está suborcinado à legislação trabalhista.

A mais antiga dessas sociedades é o Banco do Brasil, que é o principal estabelecimento de crédito do Govêrno Federal. Além das atividades bancárias comuns, aplicadas especialmente ao fomento da indústria e da agri. cultura, incumbe-lhe, juntamente com órgãos especiais do Ministério da Fazenda, o contrôle bancário, cambial, da exportação e importação em todo o país.

Outras sociedades de econcmia mista, de feição bancária visam a estımu. lar o desenvolvimento da economia nacional, como o Banco Nacional de Crédito Cooperativo, o Banco de Créditc da Amazônia e o Banco do Nordeste do Brasil. Outras mais exercem atividade no ramo de seguro, como o Instituto de Resseguros do Brasil e a Companhia Nacional de Seguro Agrícola.

E', todavia, no setor das indústrias de base, que as sociedades de economia mista se apresentam como instrumento de ação do Estado. No terreno da grande siderurgia (Companhia Siderúrgica Nacional), da mineração (Companhia do Vale do Rio Doce), do monopólic do petróleo (Petróleo Brasileiro Sociedade Anônima), da indústria de produção (Fábrica Nacional de Motores, Companhias Usinas Nacionais, Companhia Nacional de Álcalis), ou no setor da energia elétrica (Companhia Hidrelétrica do São Francisco, Companhia de Eletricidade do Amapá, Companhia de Eletricidade de Manaus e Sociedade Termelétrica do Capivari), a constituição dessas sociedades comerciais do Estado tem oferecido excelentes resultados.

As duas emprêsas da União mais recentes são a Companhia Urbanizadora da Nova Capital e a Rêde Ferroviária Federal S. A.

A primeira, constituída em setembro de 1956 , tem como objeto o planejamento e execução das obras da futura Capital da República, que se instalará, em Brasília, no Planalto Central do País, em 22 de abril de 1960. O seu capital foi totalmente subscrito pela União e integralizado mediante bens e valores em dinheiro. A administração é exercida por um Conselho de Administraçãc de 6 membros e uma Diretoria composta de um Presidente e $3 \mathrm{Di}$ retcres. A fiscalização incumbe a um Conselho Fiscal de 3 membros. Todos os membros dêsses órgãos são nomeados pelo Presidente da República mas um têrço dêles será escolhido em lista tríplice de nones indicados pelo maior partido político da oposição.

A segunda sociedade, organizada em março de 1957, reuniu tôdas as estra. das de ferro de propriedade da União, ou por ela administradas. O seu ca- 
pital social foi totalmente subscrito pela União que poderá, no entanto, admitir, como acionistas, pessoas jurídicas de direito público interno ou sociedades de economia mista ou mesmo pessoas físicas e jurídicas brasileiras, de direito privado, até o limite de $20 \%$ (vinte por cento) do capital.

A administraçáo é organizada sob forma colegiada, por meio de uma Diretoria de 7 membros, eleita em assembléia geral, com mandato de 4 anos, e assistida por um Conselho Consultivo. O Conselho Fiscal exerce, na forma da lei comercial, a fiscalização financeira da sociedade.

Merece, finalmente, ser destacada a experiência recentemente desenvol. vida pelo Banco Nacional do Desenvolvimento Econômico - que é, como vimos, uma autarquia federal no campo da cooperação financeira com a iniciativa privada.

Uma das formas dessa colaboração entre o poder público e os grupos financeiros privados consiste na participação societária, em que o Banco se apresenta como organizador, incorporador ou acicnista de sociedades comerciais, ou presta garantia a emissões de capital (underwriter).

Embora tais sociedades comercia1s conservem o regime próprio das pessoas jurídicas de direito privado, o Estado participa, indiretamente, de sua constituição e da gestão social, em virtude da colaboração financeira e da assistência técnica e administrativa decorrente do investimento bancário.

\section{FUNDAÇÕES}

As fundações são constituídas mediante escritura pública, na forma da lei civil, precedidas, porém, de ato legislativo que lhes atribui encargos administrativos, fixa-lhes a concessão de recurscs financeiros e o gôzo de prerrogativas especiais, ou autoriza a sua constituição.

São, atualmente, em número de sete, a saber:

a) Fundação da Casa Popular, destinada à construção ou financiamento de casas populares, especialmente para as classes trabalhadoras;

b) Fundação Getúlio Vargas, com a finalidade de estudos e pesquisas, planejamentos, assistência técnica e preparação de pessoal para serviços públicos e privados;

c) Fundação Brasil Central, visando a desbravar e colonizar as regiões do Brasil Central e Ocidental;

d) Fundação Abrigo do Cristo Redentor, para assistência u mendigos menores desamparados; tares;

e) Fundação Osório, com o encargo da educação de órfãos de mili-

f) Fundação Rádio Mauá, incumbida da administração de rádio oficial do Ministério do Trabalho, especialmente destinada à educação, cultura e recreação dos trabalhadores;

§) Fundação de Assistência aos Garimpeiros, com a atribuição de realizar serviços sociais nas zonas de garimpagem, visando à melhoria das condições de vida de suas populações. 
As fundações são mantidas com recursos orçamentárias da União, estabelecendo-se, para êsse fim, a destinação obrigatória de parte da receita pública.

São fiscalizadas, internamente, por Conselhas Fiscais ou Juntas de Contrôle e, ainda, externamente pelo exame de suas contas pelo Ministério Público, na forma da lei civil e pelo Tribunal de Contas da União.

Os dirigentes das Fundações são igualmente nomeados pelo Presidente da República, que também escclhe os membros dos órgãos fiscais, salvo quanto à Fundação Getúlio Vargas, que obedece a regime especial.

Nessa última fundação, a Assembléia Geral, composta pelos doadores e por um representante do Govêrno Federal, designado pelo Presidente da República, é o órgão soberano de deliberação, cabendo-lhe eleger o Presidente da Fundação, com mandato de 8 anos, assim como c Conselho Diretor e o Conselho Curador.

\section{CONCLUSÃO}

Não visa o presente relatório ao estudo doutrinário ou crítico das instituições nacionais. Como documento de trabalho, reúne informações sôbre a experiência brasileira no assunto do temário, de modo a possibilitar o ccnfronto, no plano do direito administrativo comparado, com as formas de descentralização administrativa em outros países.

A descentralização representa, no Brasil, uma parte substancial no esquema administrativo, atendendo a condições mesológicas e históricas.

O seu desenvolvimento coincide, especialmente, com a tendência de intervenção do Estado no domínio econômico e social, que não poderia se realizar, eficazmente, pelo sistema clássico da administração direta. 